\begin{tabular}{ll|l}
\hline Gazi & $\begin{array}{l}\text { GAZI iKTiSAT VE ișletME DERGisi } \\
\text { GAZi JOURNAL OF ECONOMICS \& BUSINESS }\end{array}$ & Giid \\
\hline $\begin{array}{l}\text { AKADEMIK } \\
\text { YAYINCILIK }\end{array}$ & & \\
\hline
\end{tabular}

\title{
Modelling exchange rate volatility using GARCH models
}

\author{
Basma Almisshal ${ }^{*}$, Mustafa Emir ${ }^{\text {b }}$ \\ ${ }^{a}$ PhD., Student, Karadeniz Technical University, Faculty of Economics \& Administrative Sciences-Business Administration, \\ 61220 Trabzon, TURKEY.Email: basmapal@gmail.com \\ ORCID ID: https://orcid.org/0000-0001-7885-1217 \\ ${ }^{b}$ Prof. Dr., Karadeniz Technical University, Faculty of Economics \& Administrative Sciences-Business Administration, \\ 61220 Trabzon,TURKEY.Email: memir@ktu.edu.tr \\ ORCID ID: https://orcid.org/0000-0002-2891-3085
}

\section{ARTICLE INFO \\ Received: 21.07.2020 \\ Accepted: 01.02.2021 \\ Available online: 15.02 .2021 \\ Article Type: Research article}

\section{Keywords:}

exchange rate volatility, leverage effect, ARMA, GARCH models, forecasting volatility.

\begin{abstract}
This paper aims to model the volatility of USD and EUR exchange rates against TRY for the period from January 2005 to December 2019 using the Generalised Autoregressive Conditional Heteroscedasticity (GARCH) models. Both symmetric and asymmetric models have been applied to measure factors that are related to the exchange rate returns such as leverage effect and volatility clustering. The symmetric GARCH $(1,1)$ model and the asymmetric EGARCH $(1,1)$, GJRGARCH $(1,1)$, and PGARCH $(1,1)$ have been applied to each currency against TRY. The results of this paper conclude that the most adequate model for estimating volatility of the USD/TRY exchange rates are the symmetric GARCH $(1,1)$ and asymmetric GJR-GARCH $(1,1)$ models. Moreover in USD/TRY returns, GARCH $(1,1)$ and GJR-GARCH $(1,1)$ models are the most appropriate models along with PGARCH $(1,1)$ in EUR/TRY as well. Regarding forecasting volatility, Root Mean Square Error (RMSE), Mean Absolute Error (MAE) and Mean Absolute Percentage Error (MAPE) tests have been used. Based on the results, the static forecast of GJR-GARCH $(1,1)$ is the best model in predicting the future pattern for both USD and EUR.
\end{abstract}

\section{GARCH yöntemleri kullanarak döviz kuru volatilitelerinin modellenmesi}

\section{MAKALE BİLGISI $\quad$ ÖZ}

Geliș Tarihi: 21.07.2020

Kabul Tarihi: 01.02.2021

Çevrimiçi Kullanım

Tarihi: 15.02 .2021

Makale Türü: Araştırma makalesi
$\mathrm{Bu}$ çalışmada, genelleştirilmiş otoregresif koşullu değişen varyans (GARCH) modelleri kullanılarak 2005-2019 döneminde ABD Doları (USD) ve Euro (EUR) döviz kurlarının Türk lirası (TRY) karşısında volatilitelerinin modellenmesi amaçlanmaktadır. Kaldıraç etkisi ve oynaklık kümelenmesi gibi döviz kuru getirileri ile ilgili faktörleri

\footnotetext{
* Corresponding author

Doi: https://doi.org/10.30855/gjeb.2021.7.1.001
} 


\author{
Anahtar Kelimeler: \\ döviz kuru volatilitesi, \\ kaldıraç etkisi, \\ ARMA, GARCH \\ modelleri, volatilite \\ tahmini.
}

ölçmek için hem simetrik hem de asimetrik modeller uygulanmıştır. Simetrik model olan GARCH $(1,1)$ ve asimetrik modeller olan EGARCH $(1,1)$, GJR-GARCH $(1,1)$ ve PGARCH $(1,1)$ modelleri her bir para biriminin TRY karşısında volatilitesini öngörmek için uygulanmıştır. Çalışma sonuçlarına göre, USD/TRY döviz kurlarının oynaklığını tahmin etmek için en uygun yöntem simetrik $\operatorname{GARCH}(1,1)$ ve asimetrik GJR-GARCH $(1,1)$ modeller olarak belirlenmiştir. USD/TRY modelinde olduğu gibi EUR/TRY'de PGARCH $(1,1)$ modelinin yanı sira GARCH $(1,1)$ ve GJR-GARCH $(1,1)$ modelleri en uygun modellerdir. Bununla birlikte EUR/TRY döviz kurlarının oynaklığını tahmin etmek için PGARCH $(1,1)$ modeli de anlamlı bir sonuç sunmaktadır. Tahmin oynaklığı ile ilgili olarak, Kök Ortalama Kare Hata (RMSE), Ortalama Mutlak Hata (MAE) ve Ortalama Mutlak Yüzde Hata (MAPE) testleri kullanılmıştır. Sonuçlara göre, statik GJRGARCH $(1,1)$ modelinin, hem USD hem EUR için daha yüksek bir volatilite tahmininde bulunabileceği ortaya konulmuştur.

\section{Introduction}

After the massive stagflation, combined to inflation and recession that the United States was suffering from during the 1960s; the Bretton Woods system had broken down. Meanwhile, in 1971, Richard Nixon, the president of the United States, had declared the "temporary" commentary of the USD ability to convert into gold. Afterwards, the USD replaced the gold standard as a global currency. Thenceforth, the members of the International Monetary Fund (IMF) were able to pick their preferred form of currency arrangements, but not pegging their currency's value to gold's price. These forms include; legalizing the currency to float freely, adopting the currency of another country, pegging it to another currency or a basket of currencies, participating in a currency bloc, or forming part of a monetary union (IMF.org, 2019). As a result, the exchange rate exposure issues surrounding the volatility and the risk management techniques against exchange rate loss surfaced periodically throughout the time since the late 1970s.

Various forms of statistical models have been evolved to capture the volatility effect. These models are often applied for estimating the degree of the exchange rate instability. Autoregressive Conditional Heteroskedasticity-ARCH by Engle( 1982), had been modelled as the serial correlation of returns throughout the inclusion of conditional variance as a function of the past errors and changing time. This had been done during Engle's attempts to explain the dynamic of inflation occurred in the United Kingdom. Generalised GARCH models had been developed independently by Bollerslev (1986) and Taylor (1986) respectively. Bollerslev(1986) added to Engle's model by inserting a long memory and created a more flexible lag structure by adding lagged conditional variance to the original model. The use of ARCH model in the exchange rate was first applied by Hsieh (1988) to compute daily data of five-currency's exchange rates. Friedman and Stoddard (1982) had used non-standard techniques to uncover the underlying patterns. Increasingly, the volatility in exchange rates became an interest for many researchers through using Heteroskedasticity models to study a higher volatility time series of currency exchange rates because they are considered much favorable against other stable variance models. Below is a brief on these studies in different regions.

Dritsaki (2019) examined the EUR/USD monthly exchange rate return from August 1953 until January 2017, a data set of 763 observations. Applying ARCH, GARCH, and EGARCH models the results showed that ARIMA $(0,0,1)$-EGARCH$(1,1)$ model was the recommended choice in terms of describing exchange rate returns and leverage effect. Also, $\operatorname{ARIMA}(0,0,1)$-EGARCH $(1,1)$ model static procedure provides better results on the forecasting rather than the dynamic. Nguyen (2018) in the paper, conducted an empirical study of the exchange rate volatility in Vietnam. A volume of 330 observations covering the period from January 1990 to Jun 2017 and monthly data on exchange rates of Vietnamese Dong comparing to USD, British Pound, Japanese Yen, and Canadian Dollar were used. The outcomes showed that ARMA $(1,0)-\operatorname{GARCH}(1,2)$ models were fit well in terms of capturing the mean and volatility trend of USD/VND and GBP/VND exchange rate returns. At the same time, 
the study indicated that ARMA(1,0)-GARCH(1,1) model better fitted in a quite reasonable manner to capture the mean and volatility trend of JPY/VND and CAD/VND exchange rate returns. The findings stated that the return on exchange rates failed in the Gaussian distribution test at a significant level of $1 \%$, and all four currencies return time-series to keep a high level of volatility clustering. In Epaphra's (2017) paper, they examined the behaviour of the exchange rate in Tanzania. A data set of daily Tanzanian Shilling against USD exchange rate over the period starting from 4 January 2009 till 27 July 2015 was used. The exchange rate movement had been modelled using ARCH, GARCH $(1,1)$, and EGARCH models. The paper concluded that TZS/USD exchange rates' volatility would be modelled successfully with GARCH $(1,1)$ model. Also, as for the forecasted volatility the results, it showed that GARCH $(1,1)$ had a noticeable predictive power. Ganbold et. al. (2017) in their study discussed a forecasting method in the use of $\mathrm{ARCH}$ models accompanying ARIMA, SARIMA (seasonal ARIMA) and semi-structural-SVAR in the Turkish context. By using a data set covering the period from 2005-2017 ARCH and GARCH family models (EGARCH, IGARCH, and PARCH) had been applied to forecast exchange rate volatility. The results showed EGARCH $(1,1)$ model after including dummy, was the best model in terms of forecasting exchange rate volatility. The model also succeeded to control the leverage effect. The three models of forecasting, ARIMA, SARIMA, and SVAR had been evaluated. The comparison of prediction techniques through RMSE and MAE formulas showed that SARIMA model was much accurate against the rest. And; Omari et. al. (2017) in their paper applied GARCH family models in modelling exchange rate volatility of the USD against Kenyan Shilling exchange rate of a data set of daily prices of USD/KES over a timeframe from January 2003 to December 2015. The performance of GARCH $(1,1)$ and GARCH-M symmetric models in addition to EGARCH $(1,1)$, APARCH $(1,1)$, and GJR-GARCH $(1,1)$ asymmetric models were captured. The results of the study indicated that the asymmetric APARCH, GJR-GARCH, and EGARCH models were better fit models to estimate volatility. Moreover Bosnjak et. al. (2016) in their paper examined the attitude derived by the number of ARCH models for the EUR and USD against the Croatian Kuna on daily observations of a timeframe between 1997 to 2015. The models had been evaluated using standard information criteria. The findings showed that GARCH $(2,1)$ was the most appropriate model for the EUR/HRK, and GARCH $(1,1)$ for the USD/HRK. For the estimated models, there was no significant evidence that positive and negative shocks affected the volatility of EUR/HRK and USD/HRK exchange rate returns. And finally; Karuthedath et. al. (2012) in their study aimed to understand the behaviour of foreign exchange rate in India and the appearance of volatility through using a day-to-day price of Indian Rupee against USD during a period up to forty years, from the second quarter of 1973 until 2012. The results of exchange rate volatility of Indian rupee against USD conducted through hiring ARCH family models like ARCH $(1,1) \operatorname{GARCH}(1,1) \operatorname{EGARCH}(1,1)$ TGARCH $(1,1)$ revealed that symmetric GARCH $(1,1)$ model which had the volatility of Indian foreign exchange rate was highly persistent during the forty-year timeframe.

Conclusively, this study aims to determine the US Dollar and EURO against Turkish Lira TRY exchange rate behaviour pattern using GARCH models and to make a comparison between them. USD and EUR have been chosen as the two currencies, which are widely used, and trusted currencies in the business world and both are among the world's currencies that are accepted for most international transactions. For that purpose, the paper applies part of GARCH family models using daily observations quoted from Central Bank of the Republic of Turkey TCMB from January 2005 until December 2019. So, the research hypothesis is that both USD and EUR versus TRY exchange rate volatilities can be determined using GARCH models. The volatility models applied are ARMA, ARCH, GARCH, GJR-GARCH, EGARCH, and PGARCH. In the end, the paper testes the best model for future forecasting of time series volatility. The paper is organised as follows; section 2 discusses the methodology; section 3 illustrates the data and empirical results; and finally, section 3 states the conclusion of the paper.

\section{Research methodology}

The main characteristic of financial time-series which are high-frequency values, volatility clustering, excess kurtosis, heavy-tailed distribution, leverage effect, and long memory properties (Omari et al, 2017) have been examined using the Autoregressive Conditional Heteroscedasticity $(\mathrm{ARCH})$ and its Generalised form GARCH models. In this paper different models under the GARCH 
family models have been used. In presenting these models, it is important to mention in this methodology the equations of conditional mean and the conditional variance which shall be conducted before applying the GARCH family models.

\subsection{Autoregressive moving average (ARMA)}

ARMA model is a forecasting variable technique used as one of the known methods used for employing the information generated from the available variables to predict its movements. ARMA is a combination of two separate models. These models normally explain the behaviour of a time series from two different perspectives: the autoregressive (AR) models and the moving average (MA) models. The majority of economic data are non-stationary. Thus, they must be imposed on a transformation process called "differencing" before they turn to be stationary. The transforming process in some literature is known as "integration". In brief, ARMA model presents that the series in question are being imposed to an "integration process "before being used for any analysis (Adeleye, 2019).

$$
\begin{aligned}
& M A(p): y_{t}=a_{1} e_{t-1}+\cdots+a_{p} e_{t-p}+e_{t} \\
& A R(q): y_{t}=\theta_{1} y_{t-1}+\theta_{2} y_{t-2}+\cdots+\theta_{q} y_{t-q}+e_{t} \\
& \operatorname{ARMA}(p, q): y_{t}=\sum_{i=1}^{p} a_{i} y_{t-i}+e_{t}+\sum_{i=1}^{q} \theta_{i} e_{t-i}
\end{aligned}
$$

Where is $y_{t}$ is the time series is being modelled.

\subsection{Volatility modelling}

The main purpose of modelling volatility is being able to forecast future trends. Typically, a volatility model is used to forecast the returns' absolute largeness (Engle and Patton, 2001). The symmetric and asymmetric effect of GARCH family models have been used in this paper in modelling the volatility of the exchange rate return time series of USD/TRY. Symmetric effect models such as GARCH $(p, q)$ and asymmetric effect have been captured through hiring GJR-GARCH $(p, q)$, EGARCH (p,q), and PGARCH(p.q).

\subsection{Conditional variance equation for $\mathrm{ARCH}(\mathrm{q})$}

The conditional variance equation is calculated as a constant + the previous value of the squared error:

$$
\sigma_{t}^{2}=a_{0}+a_{1} u_{t-1}^{2}+\ldots a_{i} u_{t-i}^{2}
$$

It should be noted that $\alpha_{1}$ has to be positive since $\sigma_{t}^{2}$ itself and $u_{t-1}^{2}$ has to be positive as they are squared terms. Increasing the value of $\mathrm{q}$ in $\operatorname{ARCH}(\mathrm{q})$ model where $\mathrm{q}$ is the number of lags in conditional variance equation, would eventually remove ARCH effect from residuals, and this probably is not the most parsimonious model. The parsimonious model however simply means accurately modelling a variable's DGP with the fewest possible parameters. Instead of estimating ARCH (7) model for USD and ARCH (3) for EUR, it would be better to estimate GARCH $(1,1)$ model since this is more parsimonious (uses fewer parameters in the conditional variance equation).

\subsection{Symmetric GARCH models}

The Generalised Autoregressive Conditional Heteroscedasticity-GARCH (p,q) Model, is another form of ARCH model that combines moving average element (MA) together with the autoregressive element (AR). Fundamentally, the model put in a new parameter (p) which is the number of lag variances. However, parameter (q) is the number of lag residual errors in GARCH model. In short, the model has the lag variance terms along with lag residual errors from a mean process (Bollerslev, 1986).

This model represents the conditional variance as a linear function of its lags. The general equation of the GARCH (p, q) model is given by the following formula;

$$
r_{t}=\mu+y_{t}, y_{t}=\sigma_{t} \varepsilon_{t}
$$




$$
\sigma_{t}^{2}=\omega+\sum_{i=1}^{p} a_{i} y_{t-i}^{2}+\sum_{j-1}^{q} \beta_{j} \sigma_{t-j}^{2}
$$

Where $r_{t}$ is the logarithm value of returns of the time series at time $t . \mu$ mean value of the returns, $y_{t}$ the error term. In most empirical applications the basic $\operatorname{GARCH}(1,1)$ model fits the dynamic conditional variance of the bulk of the time-series statistics in a reasonable way. $\operatorname{GARCH}(1,1)$ model's equation shown below;

$$
\sigma_{t}^{2}=\omega+a_{1} y_{t-1}^{2}+\beta_{1} \sigma_{t-1}^{2}
$$

To guarantee a positive variance in all instances, the following restricts are imposed $\omega>0$ and $a_{1}, \beta_{1} \geq 0$.

In several instances, GARCH model describes a rational model for modelling time-series and estimating volatility. Nevertheless, weaknesses of the ARCH model could be developed to capture the characteristics and dynamics of the time series much better. Thereafter, the GARCH (p, q) model was first presented by Bolleslev (1986). New GARCH related models have been invented to include the incompetence of the original GARCH and capture the different characteristics of the financial time series. (Omari et. al., 2017).

\subsection{Asymmetric GARCH models}

Practically, financial assets' returns are expressed as "bad" news rather than "good' news in general. This phenomenon known as leverage effect was first mentioned by Black (1976). The term "leverage" stems from the empirical observation that conditional variance (volatility) of an asset tends to increase when its returns marked negative. In the purpose to capture the asymmetry in return volatility or "leverage effect", another extension of GARCH models has been developed. It is widely known as the asymmetric GARCH models (Stokes et. al., 2004). This paper uses the following asymmetric GARCH models; GJR-GARCH, Exponential Generalised ARCH (EGARCH), and Power Generalised ARCH (PGARCH) model for capturing the asymmetric phenomena.

\subsubsection{Test of asymmetry, Engle and Ng test:}

For the purpose of testing the GARCH specification against asymmetry, Engle and $\mathrm{Ng}$ (1993) initiated the use of the sign-bias and size-bias tests. These tests are common in testing the effect of good and bad news on the stock returns volatility.

The best test involves the following regression:

$$
\hat{u}_{t}^{2}=\phi_{0}+\phi_{1} S_{t-1}+\phi_{2} S_{t-1} u_{t-1}+\phi_{3} S_{t-1} u_{t-1}+v_{t}
$$

Where $\widehat{u}_{t}^{2}$ denotes the squared residuals of a GARCH model fitted to the return. $\phi_{0}$ is constant, $S_{t-1}$ is a dummy variable that takes the value 1 if $u_{t-1}<0$ otherwise, $v_{t}$ is an error term and $S_{t-1}$ is defined as $1-S_{t-1}$. If $\phi_{1}$ is significant, then sign bias is present. If either $\phi_{2}$ or $\phi_{3}$ is significant, then size bias is also present.

\subsubsection{The Glosten, Jagannathan and Runkle GARCH (GJR-GARCH model)}

The GJR-GARCH model proposed by Glosten, Jagannathan, and Runkle in 1989 as a different form of asymmetric GARCH model. GJR-GARCH model allows for variances to react differently depending on the sign of the shock size it might receive. The conditional mean equation is the same as previous ARCH and GARCH models. However, the conditional variance equation is different to capture asymmetric volatility. The variance equation of GJR-GARCH (p, q) is as below;

$$
\sigma_{t}^{2}=\omega+\sum_{i=1}^{p} a_{i} y_{t-i}+\sum_{j=1}^{q} \beta_{j} \sigma_{t-j}^{2}+y_{i} I_{t-i} y_{t-i}
$$

Where $\alpha, \beta$, and $\gamma$ parameters are constant, $I$ is a dummy variable or an indicator function that takes the value of zero if $y_{t-i}$ is positive, and one otherwise. When the value of $I$ is one it indicates bad news and negative errors are leveraged. Negative or bad news has a greater effect than the positive ones (Omari et. al., 2017). The parameters of the model have to be positive and that $\alpha, \beta$, and $\gamma / 2<1$. If all leverage coefficients are zero, then GJR-GARCH model reduces to GARCH model. In other 
words, GARCH model can be compared with a GJR-GARCH model using the likelihood ratio method.

\subsubsection{The exponential GARCH (EGARCH) model}

Although GARCH models are successfully a useful tool in investigating fat-tail return distributions and the volatility clustering they are poor models in capturing the leverage effect as the conditional variance is a function of the past values not their sign only (Abdalla, 2012). Normally, stock returns are more responsive to negative shocks than positive shocks (Black, 1976). This asymmetric behaviour is defined as" leverage effect" term. It describes how the negative shock affected the rise of volatility and what if the positive shock with the same volume occurred. Meanwhile, EGARCH model, developed by Nelson (1991), captures asymmetric responses of the time-varying variance to shocks and ensures that the existence of positive sign of variance. The main form of the conditional variance is as follows;

$$
\operatorname{Ln}\left(\sigma_{t}^{2}\right)=\omega+\sum_{i=1}^{p} \beta_{i} \operatorname{Ln}\left(\sigma_{t-i}^{2}\right)+\sum_{j=1}^{q} a_{j}\left\{\mid \frac{\varepsilon_{t-1}}{\sigma_{t-1}} \|-\sqrt{\frac{2}{\pi}}\right\}-\gamma \frac{\varepsilon_{t-1}}{\sigma_{t-1}}
$$

The EGARCH model is asymmetric because the level $\left|\frac{\varepsilon_{t-i}}{\sigma_{t-i}}\right|$ included with coefficient $\gamma_{i}$. As the coefficient has a negative sign, it leads to the fact that positive shocks cause less volatility than negative shocks. In macroeconomic analysis, negative shocks usually imply bad news in financial markets, that leading to a higher uncertainty in the future (Wang, 2008). To capture asymmetric responses of the fluctuated variance to shocks, the paper considers EGARCH $(1,1)$ model, which has the following mean and variance equations;

Mean Equation

$$
r_{t}=\mu+\varepsilon_{t}
$$

Variance Equation $\quad \operatorname{Ln}\left(\sigma_{t}^{2}\right)=\omega+\beta_{1} \operatorname{Ln}\left(\sigma_{t-1}^{2}\right)+a_{1}\left\{\mid \frac{s_{t-1}}{\sigma_{t-1}} \|-\sqrt{\frac{2}{\pi}}\right\}-\gamma \frac{\varepsilon_{t-1}}{\sigma_{t-1}}$

\subsubsection{Measuring forecast accuracy}

The Root mean square error (RMSE), Mean Absolute Error (MAE) and Mean Absolute Percentage Error (MAPE) are well-known models in measuring forecast accuracy of a timeseries. The formulas of the three models are as bellow;

$$
\mathrm{RMSE}=\sqrt{\sum_{t}^{n} \frac{e_{t}^{n}}{n}}
$$

Where $e_{t}=y_{t}-\hat{y}_{t}$, with $y_{t}$ being the actual value of returns, and $\hat{y}_{t}$ being the fitted value from one of the estimated models with the same date. Finally, $n$ is the number of forecasted observations (10) days in this case.

$$
\text { MAE }=\frac{\sum_{t=1}^{n}\left|y t-x_{t}\right|}{n}
$$

Where $y_{t}$ is prediction, $x_{t}$ is the value and $n$ is the number of forecasted observations.

MAPE $=\frac{1}{n} \sum_{t=1}^{n}\left|\frac{A_{t}-F_{t}}{A_{t}}\right|$

Where $A_{t}$ is actual value, $F_{t}$ is forecast value and $n$ is the number of forecasted observations.

There are two different forms of each model; dynamic and static. Dynamic Models allow you to make a multiple-step-ahead forecast, while Static Models consist of a series of rolling single-stepahead forecasts.

\section{Bilgi ekonomisinin göstergeleri}

The return on the exchange rate of USD/TRY and EUR/TRY has been chosen as a dataset of this paper: a total of 3,709 observations for both currencies represents the working days of the period from 
1 January 2005 until 31 December 2019 in Turkey. During the timeframe of fourteen years fluctuation in the Turkish Lira's has been observed. The primary data sourced from the database of the Central Bank of the Republic of Turkey TCMB. A time series in daily format has been generated and tested for the presence of Unit Root as a stationary test before proceeding in applying GARCH family models. The Augmented Dickey-Fuller (ADF) unit root test is used with the following formula;

$$
y_{t}=\rho_{1} y_{t-1}+\rho_{2} \Delta y_{t-1}+\rho_{3} \Delta y_{t-2}+e_{t}
$$

Table 1

ADF Unit Root Test on USD/TRY Daily
Exchange Rates

\begin{tabular}{lccc}
\hline & & t-Statistic & Prob.* \\
\hline \multicolumn{2}{l}{$\begin{array}{l}\text { Augmented Dickey- } \\
\text { Fuller }\end{array}$} & & \\
\hline Test critical & & & \\
values: & $1 \%$ level & -3.431900 & \\
& $5 \%$ level & -2.862110 & \\
& $10 \%$ level & -2.567117 & \\
\hline
\end{tabular}

*MacKinnon (1996) one-sided p-values.
Table 2

\section{ADF Unit Root Test on EUR/TRY Daily Exchange Rates}

\begin{tabular}{|c|c|c|c|}
\hline & & t-Statistic & Prob.* \\
\hline $\begin{array}{l}\text { Augmented } \\
\text { Fuller }\end{array}$ & ickey- & 1.503260 & 0.9994 \\
\hline $\begin{array}{l}\text { Test critical } \\
\text { values: }\end{array}$ & $\begin{array}{l}1 \% \text { level } \\
5 \% \text { level } \\
10 \% \text { level }\end{array}$ & $\begin{array}{l}-3.431900 \\
-2.862110 \\
-2.567117\end{array}$ & \\
\hline
\end{tabular}

Source: Authors' calculation

According to the result illustrated in Table 1 and Table 2, the ADF test of USD/TRY daily rate series is $1.713>1$ and $1.503>1$ respectively. Also, both statistics are greater than the critical p-values at all significant levels of $(1 \%, 5 \%$, and $10 \%)$. Therefore, the null hypothesis of the ADF test $\mathrm{H}_{0}$ that the data have a unit root is accepted for both USD and EUR. The time series of daily exchange rate observations is non-stationary. To overcome this issue; the return on USD/TRY and EUR/TRY exchange rates are generated.

Thus, the series is converted into the exchange rate return by following a logarithmic transformation;

$$
R_{t}=\left[\ln \frac{f x_{t}}{f x_{t-1}}\right]-100 \%
$$

Where $R_{t}$ is the percentage of the return on the exchange rate, $f x_{t}$ and $f x_{t-1}$ is the exchange rate of the current and the previous period that the exchange rate is being observed.

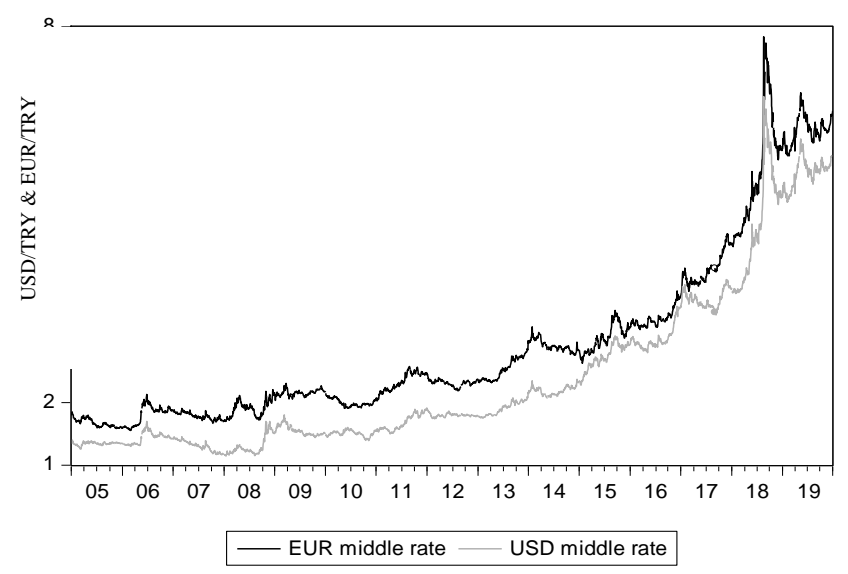

Fig. 1. Time series of the USD/TRY and EUR/TRY daily middle exchange rates for the period 01.01.2005 till 31.12.2019. Source: Central Bank of the Republic of Turkey 


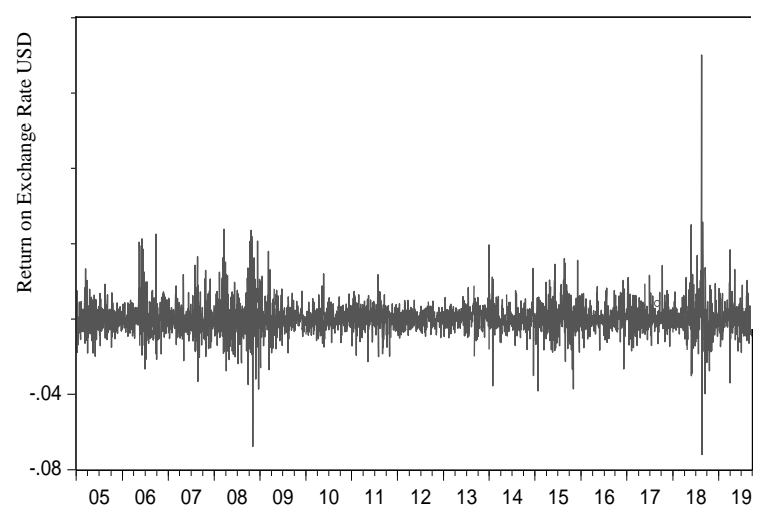

Fig. 2. Return on Exchange Rate of USD/TRY for the period 01.01.2005 till 31.12.2019.

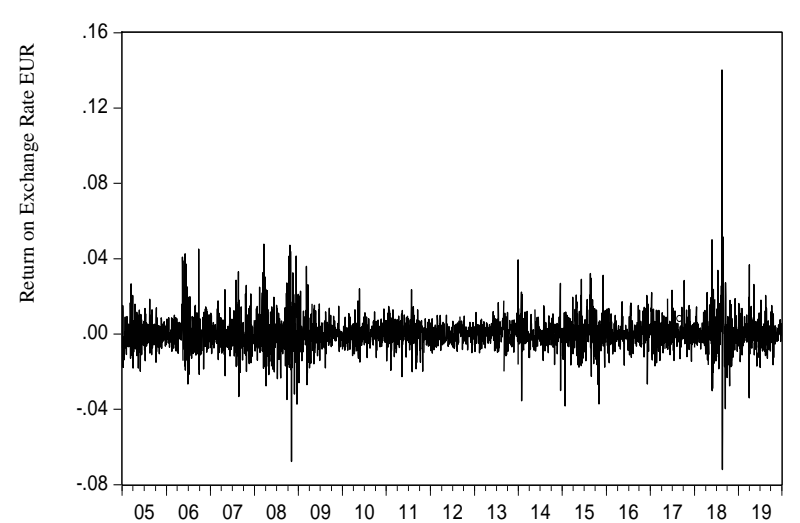

Fig. 3. Return on Exchange Rate of EUR/TRY for the period 01.01.2005 till 31.12.2019.

Figure 1 illustrates the time series of the daily exchange rates of USD/TRY and EUR/TRY. It is obvious from the graph that the plots are non-stationary for the two currencies against TRY and follow a random walk. However, a modified plot of the log-returns series for the exchange rates of USD/TRY in Figure 2 and EUR/TRY in Figure 3 show that return rates are not constant over the timeframe of this study. One is at the end of October 2008 and the other is on the mid of August 2018. The two figures also show overall massive increases of volatility. As a result of that, decreasing slope of exchange rate is always followed by high volatility. This percentage is known as the leverage effect (Abdalla, 2012). The ADF test has been recalculated to test the stationarity in the return series. The results in Table 3 and Table 4 show ADF of (-57.02) and (-37.36) which are much smaller than all the significance $\mathrm{p}$-values and the $\mathrm{H}_{0}$ is (return) rejected.

Table 3

ADF Unit Root Test on the Modified Time Series of USD/TRY Exchange Rate Return

\begin{tabular}{crrr}
\hline & & t-Statistic & Prob.* \\
\hline Augmented Dickey-Fuller & -57.02171 & 0.0001 \\
\hline Test critical & $1 \%$ level & -3.431898 & \\
values: & $5 \%$ level & -2.862109 & \\
& & & \\
& $10 \%$ level & -2.567116 &
\end{tabular}

*MacKinnon (1996) one-sided p-values.
Table 4

ADF Unit Root Test on the Modified Time Series of EUR/TRY Exchange Rate Return

\begin{tabular}{|c|c|c|c|}
\hline & & t-Statistic & Prob.* \\
\hline Augmented Di & key-Fuller & -37.35721 & 0.0000 \\
\hline $\begin{array}{l}\text { Test critical } \\
\text { values. }\end{array}$ & $1 \%$ level & -3.431899 & \\
\hline & $5 \%$ level & -2.862110 & \\
\hline & $10 \%$ level & -2.567117 & \\
\hline
\end{tabular}

*MacKinnon (1996) one-sided p-values.

Source: Authors' calculation

Table 5 shows the descriptive statistics of the return series. A positive mean value is shown in both USD and EUR. The series exhibits volatility clustering considering that USD/TRY and EUR/TRY exchange rate returns witnessed periods when large changes are following with further large changes and periods when small changes are followed by further small changes. The coefficient of skewness of 1.1857 and 1.4124 respectively indicate that returns have asymmetric distribution in both cases. The kurtosis of returns in both statistics is bigger than 3. Distributions with kurtosis greater than 3 are said to be leptokurtic. The non-normality condition is supported by a Jarque-Bera (JB) test. The results are high, which lead to the rejection of the null hypothesis of normality at the significance level of 5\%. In other words, the errors are not normally distributed. 
Table 5

Descriptive Statistic of the USD/TRY and EUR/TRY Exchange Rate Return

\begin{tabular}{ccccccccc}
\hline & $\mathrm{N}$ & Min & Max & Mean & Std. D. & Skewness & Kurtosis & JB test \\
\hline $\mathrm{r}_{\text {USD }}$ & 3,773 & -0.1194 & 0.1471 & 0.000395 & 0.0091 & 1.1857 & 35.855 & $170,579.0$ \\
$\mathrm{r}_{\text {EUR }}$ & 3,773 & -0.0719 & 0.1402 & 0.000343 & 0.0087 & 1.4142 & 28.485 & $103,364.1$ \\
\hline
\end{tabular}

Source: Authors' calculation

\subsection{Ljung-Box test}

The Ljung-Box Q test was named after Greta Marianne Ljung and her university's advisor George E. P. Box. Ljung-Box Q test is a portmanteau test that is based on the autocorrelation plot. It is a widely used test in economics to test for serial correlation in time series and to determine whether there is a structure in a time series worth modelling or not. It also applies to residuals after a forecast model has been fit to data. The Ljung-Box test formula is;

$$
Q=n(n+2) \sum_{i=1}^{k} \frac{r_{i}^{2}}{m-i}
$$

Where $Q$ is the Ljung-Box statistics, $r_{i}$ is the estimated autocorrelation between observations separated by $\mathbf{i}$ time and $k$ is the degree of freedom. According to the results of Ljung-Box and Q-test where the null hypothesis $\mathrm{H}_{0}$ is that all correlation up to lags $k$ is equal to 0 , the series of exchange rate return show significant autocorrelation as shown in p-value which at any $k$ is less than 0.05 . Therefore the null hypothesis is rejected and the series are correlated.

\subsection{Estimating mean equation}

Autoregressive Moving Average model (ARMA) is used to describe the mean returns, as it provides flexible and parsimonious approximation to conditional mean dynamics. To choose the appropriate model, it can be chosen among several factors like having the most significant coefficient, the least volatility, the highest adjusted R-squared, and finally the lowest of both Akaike Information Criterion AIC and Schwarz criterion SBIC. In this paper as shown in Table 6 and Table 7, the essential statistics for ARMA (p,q) are listed in which among wider analysis best four ARMA (p,q) models have been chosen per each currency against TRY to choose the best ARMA equation.

\section{Table 6}

\section{Comparison for ARMA (p, q) for Best Selection - USD/TRY}

\begin{tabular}{ccccc}
\hline $\begin{array}{c}\text { Return on } \\
\text { Exchange rate }\end{array}$ & ARMA $(3,0)$ & ARMA $(0,1)$ & ARMA $(3,1)$ & ARMA $(5,2)$ \\
\hline Significant & 2 & 1 & 4 & 5 \\
Coefficient & 8.305197 & 8.322311 & 8.292686 & 8.238736 \\
Sigma2 Volatility & 0.005625 & 0.004059 & 0.007518 & 0.012331 \\
Adj. R2 & -6.557868 & -6.555578 & -6.559509 & -6.565166 \\
AIC & -6.552907 & -6.553926 & -6.552894 & -6.553585 \\
SBIC & &
\end{tabular}


Table 7

Comparison for ARMA (p, q) for Best Selection - EUR/TRY

\begin{tabular}{ccccc}
\hline Return on Exchange rate & ARMA $(0,3)$ & ARMA $(1,3)$ & ARMA $(2,2)$ & ARMA $(3,1)$ \\
\hline Significant Coefficient & 3 & 3 & 4 & 3 \\
Sigma2 Volatility & 7.484738 & 7.471631 & 7.486616 & 7.472274 \\
Adj. R2 & 0.013981 & 0.015452 & 0.014890 & 0.015519 \\
AIC & -6.660598 & -6.661753 & -6.661111 & -6.662241 \\
SBIC & -6.655640 & -6.655140 & -6.654498 & -6.655626 \\
\hline
\end{tabular}

Source: Authors' calculation

As for USD/TRY shown in Table 6, the statistics indicate that ARMA $(5,2)$ has the most appropriate ARMA model in this case with the highest number of significant coefficients at $5 \%$ level, and highest adjusted R-squared, in contrast, ARMA $(5,2)$ has the lowest volatility and AIC and the second-lowest SBIC after ARMA $(0,1)$. Likewise, EUR/TRY statistics in Table 7 also assigned that ARMA $(3,1)$ is the most appropriate ARMA model that minimizes the short information criteria.

3.3 Testing for heteroscedasticity

The highest priority before testing GARCH model is to look for evidence of heteroscedasticity throughout examining the residuals of the return series. To test for it, the Lagrange Multiplier (LM) test proposed by Engle (1982) has been applied. Based on the result of ARCH effect test the null hypothesis $\mathrm{H}_{0}$ is that there is no ARCH effect presented in the model. It has been rejected and ARCH effect is considered at a significant level of $5 \%$.

Now, the following Table 8 and Table 9 summarize the GARCH models results of both USD and EUR volatility against TRY respectively;

Table 8

Symmetric and Asymmetric Models' Results of USD/TRY Exchange Rates

\begin{tabular}{|c|c|c|c|c|c|c|c|}
\hline Model & Parameter & Coefficient & Std. Error & z-statistic & $\mathrm{p}$-value & ARCH LM & $\begin{array}{l}\text { Schwartz } \\
\text { Criterion } \\
\end{array}$ \\
\hline \multirow{3}{*}{ GARCH $(1,1)$} & a & 2.300544 & 2.359925 & 9.748377 & 0.0000 & \multirow{3}{*}{$\begin{array}{l}1.491967 \\
(0.2219)\end{array}$} & \multirow{3}{*}{-6.972931} \\
\hline & $\mathrm{u}^{2}$ & 0.168218 & 0.009543 & 17.62781 & 0.0000 & & \\
\hline & $\sigma^{2}$ & 0.805366 & 0.007397 & 108.8831 & 0.0000 & & \\
\hline \multirow{4}{*}{$\begin{array}{c}\text { GJR-GARCH } \\
(1,1)\end{array}$} & $\mathrm{a}$ & 1.296788 & 1.500463 & 8.642583 & 0.0000 & \multirow{4}{*}{$\begin{array}{l}3.46283 \\
(0.0628)\end{array}$} & \multirow{4}{*}{-6.987574} \\
\hline & $u^{2}$ & 0.164868 & 0.008817 & 18.69895 & 0.0000 & & \\
\hline & $\Upsilon$ & -0.099352 & 0.010516 & -9.447524 & 0.0000 & & \\
\hline & $\sigma^{2}$ & 0.867781 & 0.006427 & 135.0209 & 0.0000 & & \\
\hline \multirow{4}{*}{ EGARCH $(1,1)$} & $\omega$ & -0.425897 & 0.024950 & -17.06974 & 0.0000 & \multirow{4}{*}{$\begin{array}{l}9.650463 \\
(0.0019)\end{array}$} & \multirow{4}{*}{-6.985476} \\
\hline & $\alpha$ & 0.214947 & 0.011047 & 19.45789 & 0.0000 & & \\
\hline & r & 0.078262 & 0.006984 & 11.20570 & 0.0000 & & \\
\hline & $\beta$ & 0.973421 & 0.002365 & 411.5768 & 0.0000 & & \\
\hline \multirow{5}{*}{ PGARCH } & $\omega$ & 8.488113 & 5.052334 & 1.680038 & 0.0929 & \multirow{5}{*}{$\begin{array}{l}5.275598 \\
(0.0216)\end{array}$} & \multirow{5}{*}{-6.986743} \\
\hline & $\alpha$ & 0.115732 & 0.008500 & 13.61593 & 0.0000 & & \\
\hline & r & -0.280704 & 0.037323 & -7.521040 & 0.0000 & & \\
\hline & $\beta$ & 0.873271 & 0.006160 & 141.7679 & 0.0000 & & \\
\hline & $\delta$ & 1.633621 & 0.113898 & 14.34289 & 0.0000 & & \\
\hline
\end{tabular}


Table 9

Symmetric and Asymmetric Models' Results of EUR/TRY Exchange Rates

\begin{tabular}{|c|c|c|c|c|c|c|c|}
\hline Model & Parameter & Coefficient & Std. Error & z-statistic & $\mathrm{p}$-value & $\begin{array}{c}\text { ARCH } \\
\text { LM }\end{array}$ & $\begin{array}{l}\text { Schwartz } \\
\text { Criterion }\end{array}$ \\
\hline \multirow{3}{*}{ GARCH $(1,1)$} & $\mathrm{a}$ & 2.809435 & 2.636117 & 10.65748 & 0.0000 & \multirow{3}{*}{$\begin{array}{c}3.307463 \\
(0.0690)\end{array}$} & \multirow{3}{*}{-7.040759} \\
\hline & $\mathrm{u}^{2}$ & 0.187783 & 0.009452 & 19.86739 & 0.0000 & & \\
\hline & $\sigma^{2}$ & 0.782566 & 0.010113 & 77.37913 & 0.0000 & & \\
\hline \multirow{4}{*}{$\begin{array}{c}\text { GJR-GARCH } \\
(1,1)\end{array}$} & $\mathrm{a}$ & 2.617629 & 2.587766 & 10.11540 & 0.0000 & \multirow{4}{*}{$\begin{array}{c}1.680007 \\
(0.1949)\end{array}$} & \multirow{4}{*}{-7.056927} \\
\hline & $\mathrm{u}^{2}$ & 0.234311 & 0.012600 & 18.59580 & 0.0000 & & \\
\hline & $\Upsilon$ & -0.156353 & 0.012396 & -12.61348 & 0.0000 & & \\
\hline & $\sigma^{2}$ & 0.805673 & 0.010726 & 75.11279 & 0.0000 & & \\
\hline \multirow{4}{*}{ EGARCH } & $\omega$ & -0.636669 & 0.041681 & -15.27473 & 0.0000 & \multirow{4}{*}{$\begin{array}{c}8.303869 \\
(0.0040)\end{array}$} & \multirow{4}{*}{-7.054059} \\
\hline & $\alpha$ & 0.264540 & 0.013286 & 19.91051 & 0.0000 & & \\
\hline & $\Upsilon$ & 0.093485 & 0.006826 & 13.69581 & 0.0000 & & \\
\hline & $\beta$ & 0.956075 & 0.003753 & 254.7617 & 0.0000 & & \\
\hline \multirow{5}{*}{ PGARCH } & $\omega$ & 2.002498 & 1.135208 & 1.763993 & 0.0777 & \multirow{5}{*}{$\begin{array}{c}3.725402 \\
(0.0536)\end{array}$} & \multirow{5}{*}{-7.056097} \\
\hline & $\alpha$ & 0.149117 & 0.010128 & 14.72283 & 0.0000 & & \\
\hline & $\Upsilon$ & -0.319507 & 0.032489 & -9.834242 & 0.0000 & & \\
\hline & $\beta$ & 0.823922 & 0.009752 & 84.48431 & 0.0000 & & \\
\hline & $\delta$ & 1.580491 & 0.111050 & 14.23228 & 0.0000 & & \\
\hline
\end{tabular}

Note: $\omega$ is constant, $\alpha$ is ARCH term, $\Upsilon$ is Leverage term, $\beta$ is GARCH term and $\delta$ is Power term.

Source: Authors' calculation

\subsubsection{GARCH $(1,1)$ model}

As for GARCH $(1,1)$ model; both the ARCH and GARCH parameters in both USD and EUR statistics are highly significant with a p-value of 0.000 in both of them. The sum of the coefficient of the ARCH and GARCH parameters $(0.168218+0.805366),(0.187783+0.782566)$ respectively are very close to 1 which means that the shocks to the conditional variances will be highly persistent. Since the GARCH parameter is significant, a large return value (either negative or positive) will lead future forecasts of the variance to be high for a prolonged period. This means the GARCH model will be a better forecasting model than ARCH model in periods of high volatility.

The Ljung-box test shows that GARCH $(1,1)$ has no ARCH effect in both currencies. After estimating the GARCH $(1,1)$ model asymmetric GARCH models have been estimated for both USD/TRY and TYR/EUR return on exchange rates series. For that purpose The Engle and NG test has been conducted. The Engle and NG test is a good way of determining whether there is sign bias or size bias present in the volatility of the returns of the variables. If any significant value is found from the test, this is a good justification for estimating some asymmetric GARCH models afterwards.

Table 10

\section{Results of Engle and NG Test - TRY Versus USD and EUR}

\begin{tabular}{cccccc}
\hline Engle and NG Test & Variable & Coefficient & Std. Error & t-Statistic & P-value \\
\hline USD/TRY & $\mathrm{C}$ & -6.082912 & 1.354203 & -4.491874 & 0.0000 \\
& $\overline{\mathrm{S}}_{\mathrm{USD}-1}$ & 4.395050 & 1.940208 & 2.265247 & 0.0236 \\
& $\mathrm{~S}-\mathrm{USD}_{\mathrm{US}-1} \mathrm{u}_{\mathrm{USD}-1}$ & -0.014654 & 0.001707 & -8.587342 & 0.0000 \\
& $\mathrm{~S}+_{\mathrm{USD}-1} \mathrm{u}_{\mathrm{USD}-1}$ & 0.025697 & 0.001357 & 18.94095 & 0.0000 \\
\hline $\mathrm{CUR} / \mathrm{C} \mathrm{C} Y$ & $\overline{\mathrm{S}}$ & -5.386889 & 1.031686 & -5.221442 & 0.0000 \\
& $\mathrm{~S}-{ }_{\mathrm{EUR}-1} \mathrm{u}_{\mathrm{EUR}-1}$ & -0.011442 & 0.001379 & -8.298124 & 0.0000 \\
& $\mathrm{~S}+_{\mathrm{EUR}-1} \mathrm{u}_{\mathrm{EUR}-1}$ & 0.024156 & 0.001105 & 21.85540 & 0.0000 \\
\hline
\end{tabular}

Source: Authors' calculation 
The coefficient for $\bar{S}_{U S D-1}$ has p-values of 0.0236 and for $\bar{S}_{E U R-1} 0.0006$ which demonstrates that it is significant at 5\% level. This is a strong indication of sign bias. Moreover, the coefficient for $S-{ }_{t-1} u_{t-1}$ and $S+_{t-1} u_{t-1}$ are both in USD and EUR statistics significant with p- values of 0.000 . This is a strong indicator of size bias. The test result in Table 10 serves as a good justification for estimating GARCH models which allow for asymmetric volatility.

\subsubsection{GJR GARCH $(1,1)$ model}

In asymmetric GJR GARCH model (1989), importantly, the coefficient $\gamma$ is noticed negative of 0.099352 and -0.156353 respectively; as shown in Table 8 and Table 9. This suggests that the leverage effect is not present, and it is statistically significant with a p-value of 0.000 . The other terms in the conditional variance equation are statistically significant. In contrast, the ARCH LM test and the Qtest both are not significant at level of $5 \%$ with heteroscedasticity and autocorrelation affecting the series. Therefore, a weak argument can be made that the leverage effect is presented.

\subsubsection{EGARCH $(1,1)$ model}

If $\gamma$ is statistically significant and has a negative sign, this implies that a fall in returns results in greater volatility than an increase in returns of the same magnitude (leverage effect).

The significance of the terms $\alpha_{0}$ which is the ARCH term, has a p-value of 0.000 . Therefore, the size of the shock has a significant impact on the volatility of returns. $Y$ (The leverage effect term) is significant at a level of 5\%, which encourages an argument that the sign of the shock has an impact of volatility of returns. $\beta$ has a p-value of 0.000 . Therefore, past volatility helps to predict future volatility.

The signs of the terms $\alpha$, which is positive, shows there is a positive relationship between the past variance and the current variances in absolute value. This means the bigger the magnitude of the shock to the variance, the higher the volatility. $\gamma$ is also positive which indicates that both good and bad news will increase the volatility of the small size evidence of leverage effect.

\subsubsection{PGARCH $(1,1)$ model}

The Power GARCH (PGARCH) model of Ding, Granger, and Engle (1993) represents a flexible alternative that allows a bigger range of power transformations rather than adopting the absolute value or squaring the data as in other classical heteroskedastic models (Anè, 2006). In Table 8 and Table $9, \alpha$ is ARCH term, $\Upsilon$ is Leverage term and is negative and approves leverage effect. $\beta$ is GARCH term and $\delta$ is Power term and is significant at $5 \%$ of the p-value of 0.000 , like in GJR-GARCH model which shows autocorrelated series in Q-test result.

\section{Table 11}

Results of Modelling Metrics USD/TRY

\begin{tabular}{ccccc}
\hline Modelling Metrics & GARCH(1,1) & GJRGARCH(1,1) & EGARCH(1,1) & P-GARCH $(1,1)$ \\
\hline Adjusted R-squared & 0.003733 & 0.005454 & 0.005961 & 0.005685 \\
Log likelihood & 13178.17 & 13209.88 & 13205.93 & 13212.43 \\
Akaike info criterion & -6.989476 & -7.005774 & -7.003676 & -7.006598 \\
Schwarz criterion & -6.972931 & -6.987574 & -6.985476 & -6.986743 \\
\hline
\end{tabular}


Table 12

Results of Modelling Metrics EUR/TRY

\begin{tabular}{ccccc}
\hline Modelling Metrics & GARCH(1,1) & GJRGARCH(1,1) & EGARCH(1,1) & P-GARCH $(1,1)$ \\
\hline Adjusted R-squared & 0.010911 & 0.009531 & 0.009472 & 0.009325 \\
Log likelihood & 13300.65 & 13335.25 & 13329.84 & 13337.8 \\
Akaike info criterion & -7.052335 & -7.070157 & -7.06729 & -7.070982 \\
Schwarz criterion & -7.040759 & -7.056927 & -7.054059 & -7.056097 \\
\hline
\end{tabular}

Source: Authors' calculation

Based on the results in Table 8 the ARCH LM test results for both EGARCH and PGARCH models indicated rejection of the null hypothesis in a significant level of 5\%. Thus, looking at the results in Table 11 symmetric GARCH $(1,1)$ and asymmetric GJR-GARCH $(1,1)$ achieve the requirements and has been marked as best volatility models for USD/TRY exchange rate return in this paper based on highest Adjusted R2 and lower AIC and SC, with a predilection in GJRGARCH $(1,1)$ model over the GARCH $(1,1)$. However, the literature stated that when it comes to model the exchange rate volatility, symmetric GARCH models perform better than asymmetric GARCH models (Arachchi, 2018).

Furthermore, in Table 9 as for EUR/TRY, EGARCH $(1,1)$ has been eliminated as the p-value of the ARCH LM test is below the significant level of 5\% in which the null hypothesis is rejected for the presence of heteroscedasticity. Among the remaining models Table 12 illustrated symmetric GARCH $(1,1)$ and both asymmetric models GJR-GARCH $(1,1)$ and PGARCH $(1,1)$ achieve the requirements with highest Adjusted $\mathrm{R}^{2}$ and lower AIC and SC metrics and have been marked as best volatility models for EUR/TRY exchange rate return in this paper.

\subsection{Forecasting volatility}

Ultimately the whole point of estimating all of these ARCH/GARCH models is to see whether future returns of any kind of asset can be predicted or not. A good format for evaluating which model is best three method has implemented; Root Mean Square Error test (RMSE), Mean Absolute Error (MAE) and Mean Absolute Percentage Error (MAPE). The results of each test in both dynamic and static forecasts are as follows;

\section{Table 13}

Forecasting the Best GARCH of USD/TRY Model of Volatility

\begin{tabular}{ccccc} 
Forecast Type & & RMSE & MAE & MAPE \\
\hline \multirow{2}{*}{ GARCH $(1,1)$} & Dynamic & 0.003210 & 0.002456 & 99.757690 \\
& Static & 0.003160 & 0.002456 & 108.353400 \\
\hline \multirow{2}{*}{ GJR-GARCH $(1,1)$} & Dynamic & 0.003189 & 0.002418 & 90.522390 \\
& Static & 0.003122 & 0.002376 & 92.186660 \\
\hline \multirow{2}{*}{ EGARCH $(1,1)$} & Dynamic & 0.003251 & 0.002437 & 89.772840 \\
& Static & 0.003199 & 0.002409 & 96.034140 \\
\hline \multirow{2}{*}{ PGARCH $(1,1)$} & Dynamic & 0.003192 & 0.002419 & 89.775040 \\
& Static & 0.003127 & 0.002381 & 92.434300 \\
\hline
\end{tabular}


Table 14

Forecasting the Best GARCH of EUR/TRY Model of Volatility

\begin{tabular}{ccccc} 
Forecast Type & & RMSE & MAE & MAPE \\
\hline \multirow{2}{*}{ GARCH $(\mathbf{1 , 1})$} & Dynamic & 0.003898 & 0.003102 & 98.894920 \\
& Static & 0.003738 & 0.003051 & 149.449900 \\
\hline \multirow{2}{*}{ GJR-GARCH $(\mathbf{1 , 1})$} & Dynamic & 0.003864 & 0.003075 & 98.414420 \\
& Static & 0.003697 & 0.003007 & 142.631500 \\
\hline \multirow{2}{*}{ EGARCH $(\mathbf{1 , 1})$} & Dynamic & 0.003908 & 0.003123 & 116.042800 \\
& Static & 0.003761 & 0.003076 & 164.079700 \\
\hline \multirow{2}{*}{ PGARCH $(\mathbf{1 , 1})$} & Dynamic & 0.003862 & 0.003074 & 98.381290 \\
& Static & 0.003698 & 0.003007 & 140.545800 \\
\hline
\end{tabular}

Source: Authors' calculation

Looking at Table 13 and Table 14 of the tests' results, RMSE, MAE and MAPE in dynamic and static forecast types have been evaluated for the studied GARCH models. Although the results are critically near to each other in both cases, the best model to obtain the best forecasting model is the model with lowest RMSE, MAE and MAPE. In this case, GJR-GARCH $(1,1)$ static with the lowest RMSE ratio of 00.003122 and 00.003697 respectively for both USD and EUR and lowest MAE ratio of 0.002376 and 0.003007 respectively for both USD and EUR, is the best GARCH model. In regards to MAPE, it records the lowest ratio in EGARCH $(1,1)$ model by 89.772840 and PGARCH $(1,1)$ model by 98.381290 for USD and EUR respectively. Actually, MAPE is quite well-known as a poor accuracy indicator, as it tends to divide each error over demand one by one. As a result, high errors during low-demand periods will significantly impact MAPE thus it is skewed. However, MAPE causes strange forecast (Vandeput, 2019). That is the reason the paper has ignored MAPE results.

In Figure 4 and 5 the graphs show how accurate is the selected model (GARCH dynamic) in this study for predicting future volatility in USD/TRY and EUR/TRY exchange rate returns.

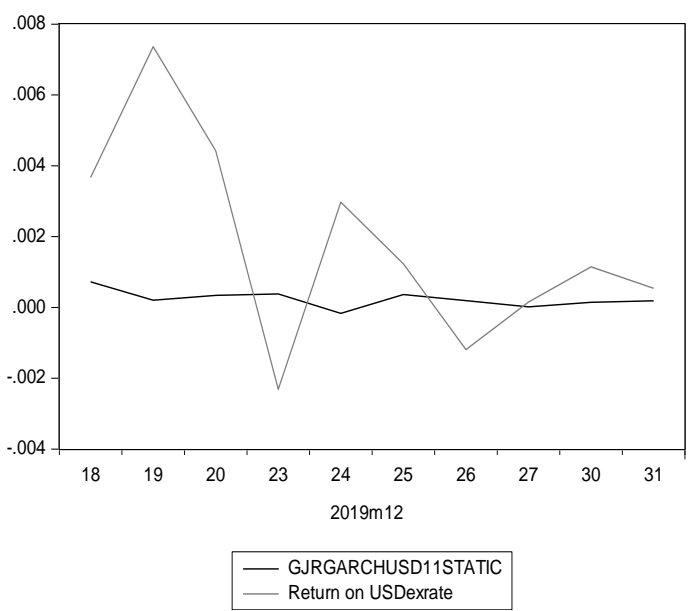

Fig. 4. Shows The Best Forecast Model Of 10 Days Period for USD/TRY - GJR-GARCH $(1,1)$

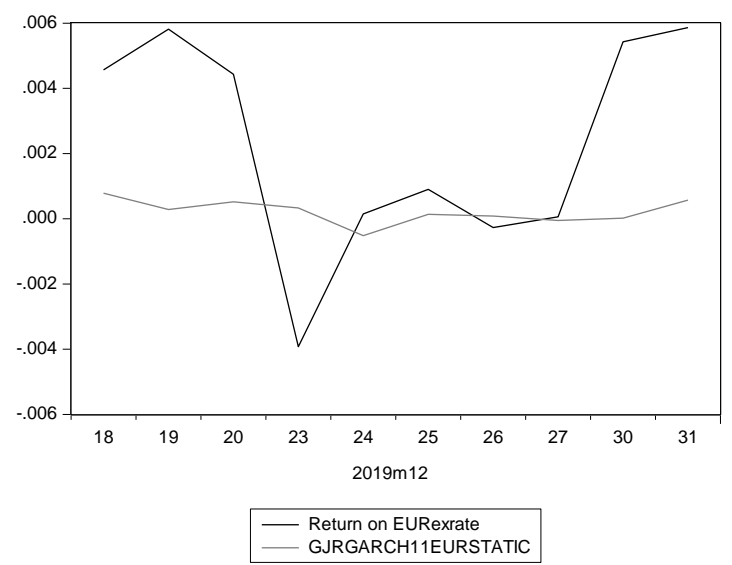

Fig. 5. Shows The Best Forecast Model Of 10 Days Period for EUR/TRY -PGARCH $(1,1)$

Source: Authors' calculation

\section{References}

Abdalla, S. Z. S. (2012). Modeling exchange rate volatility using GARCH models: empirical evidence from Arab countries. International Journal of Economics and Finance. DOI: 10.5539/ijef.v4n3p216.

Adeleye, N. (2019). Eviews Time series Videos. Crunch Econometrix Youtube Channel. Retrieved on 18 December, 2019 from https://www.youtube.com/channel/UCK9hD254JKbCZ4Bf8Iz1s7g. 
Ané, T. (2006). An analysis of the flexibility of Asymmetric Power GARCH models. Computational Statistics \& Data Analysis. DOI: 10.1016/j.csda.2005.11.002.

Arachchi, K. (2018). Comparison of symmetric and asymmetric GARCH models: Application of exchange rate volatility. American Journal of Mathematics and Statistics. DOI:10.5923/j.ajms.20180805.08.

Black, F. (1976). Studies of stock price volatility changes. Proceedings of the business and economics section of the American statistical association, 177-181.

Bollerslev, T. (1986). Generalised autoregressive conditional heteroskedasticity. Journal of Econometrics, 31(3). DOI: $10.1016 / 0304-4076(86) 90063-1$.

Bollerslev, T. (1990). Modelling the coherence in short-run nominal exchange rates: a multivariate Generalised ARCH model. Review of Economics and Statistics, 72(3). DOI: 10.2307/2109358.

Bosnjak, M., Bilas, V. and Novak, I. (2016). Modeling exchange rate volatilities in Croatia. Ekonomski Vijesnik/Econviews-Review of Contemporary Business, Entrepreneurship and Economic Issues, 29(1), 81-94.

Central Bank of the Republic of Turkey(2020). Historical exchange rates in EVDS data central. Retrieved on 8 January, 2020 from https://www.tcmb.gov.tr/.

Dritsaki, C. (2019). Modeling the volatility of exchange rate currency using GARCH model. International Economics, 72(2), 209-230.

Engle, R. and Patton, A. (2001). What good is a volatility model?. Quantitative Finance, 1(2), 237-245. DOI:10.1088/1469-7688/1/2/305.

Engle, R.F. and Ng, V.K. (1993). Measuring and testing the impact of news on volatility. Journal of Finance, 48, 1749-1801. DOI: 10.1111/j.1540-6261.1993.tb05127.x

Epaphra, M. (2017). Modeling exchange rate volatility: application of the GARCH and EGARCH models. Journal of Mathematical Finance, 7, 121-143. DOI: 10.4236/jmf.2017.71007

Friedman, D., and Stoddard, V. (1982). Short-run fluctuations in foreign exchange rates: evidence from the data 1973-1979. Journal of international Economics, 13, 171-186. DOI: 10.1016/0022-1996(82)90012-5

Ganbold, B., Akram, I. and Fahrozi Lubis, R. (2017). Exchange rate volatility: A forecasting approach of using the ARCH family along with ARIMA SARIMA and semi-structural-SVAR in Turkey. University Library of Munich, MPRA Paper No. 87447.

Glosten, L., Jagannathan R., and Runkle D. (1993), Relationship between the expected value and the volatility of the nominal excess return on stocks. The Journal of Finance, 48 (5). Published by: Blackwell Publishing for the American Finance Association. DOI: 10.1111/j.1540-6261.1993.tb05128.x.

Göksu, A. and Ergun, U. (2013). Applied econometrics with Eviews applications. First edition, International Burch University, Sarajevo.

Hsieh, D.A. (1989). Modeling heteroscedasticity in daily foreign-exchange rates. Journal of Business and Economic Statistics, 7, 307-317. DOI: 10.1080/07350015.1989.10509740.

International Monetary Fund(2019). The End of the Bretton Woods System (1972-81). Retrieved on 22 December, 2019 from https://www.imf.org/external/about/histend.htm.

Karuthedath, Samsudheen K. and Shanmugasundaram, G. (2012). Foreign Exchange Rate Volatility of Indian Rupee/US Dollar. XI Capital Markets Conference, 21-22, Indian Institute of Capital Markets (UTIICM). DOI: $10.2139 / \mathrm{ssrn} .2258366$.

Nguyen T.K.D. (2018). Modelling exchange rate volatility using GARCH model: an empirical analysis for Vietnam. Econometrics for Financial Applications. Studies in Computational Intelligence, 760. Springer, Cham. DOI: 10.1007/978-3-319-73150-6_69.

Omari, C., Mwita, P. and Waititu, A. (2017). Modeling USD/KES exchange rate volatility using GARCH Models. IOSR Journal of Economics and Finance (IOSR-JEF), 8, 2321-5933. DOI: 10.9790/59330801011526

Stokes, H. H., Liu, L. M., and Lattyak, W. J. (2004). General Autoregressive Conditional Heteroscedastic (GARCH) Modeling Using SCAB34S-GARCH and SCA WorkBench, Scientific Computing Associates Corp. University of Illinois at Chicago. 
Taylor, S. J. (1987). Forecasting the volatility of currency exchange rates. International Journal of Forecasting, 3, 159 - 70. DOI: 10.1016/0169-2070(87)90085-9.

Vandeput, N. (2019). Forecast KPIs: RMSE, MAE, MAPE \& Bias. Towards Data Science Website, Retrieved on 29 January, 2021 from https://towardsdatascience.com.

Wang, P. (2008). Financial Econometrics. Financial Econometrics. Second Edition, Routledge Advanced Texts in Economics and Finance. 